\title{
Development of a National Caregiver Health Survey for Hematopoietic Stem Cell Transplant: Qualitative Study of Cognitive Interviews and Verbal Probing
}

Jacob Kedroske ${ }^{1}$; Sarah Koblick ${ }^{1}$, MD; Dima Chaar ${ }^{2}$, MHI; Amanda Mazzoli ${ }^{1}$, BSc; Maureen O'Brien ${ }^{3}$, BA, MSW; Lilian Yahng ${ }^{4}$, BA; Rebecca Vue ${ }^{1}$; Grant Chappell ${ }^{1}$, BSc; Ji Youn Shin ${ }^{5}$, BFA, MDes; David A Hanauer ${ }^{6}$, MSc, MD; Sung Won $\mathrm{Choi}^{1}$, MSc, MD

\footnotetext{
${ }^{1}$ Blood and Marrow Transplantation Program, University of Michigan, Ann Arbor, MI, United States

${ }^{2}$ School of Public Health, University of Michigan, Ann Arbor, MI, United States

${ }^{3}$ Institute for Social Research, Survey Research Operations, University of Michigan, Ann Arbor, MI, United States

${ }^{4}$ Center for Survey Research, Indiana University, Bloomington, IN, United States

${ }^{5}$ College of Communication Arts and Sciences, Michigan State University, East Lansing, MI, United States

${ }^{6}$ Michigan Institute for Clinical and Health Research, University of Michigan, Ann Arbor, MI, United States
}

\section{Corresponding Author:}

Sung Won Choi, MSc, MD

Blood and Marrow Transplantation Program

University of Michigan

1500 E Medical Center Drive

Ann Arbor, MI, 48109

United States

Phone: 17346155707

Email: sungchoi@med.umich.edu

\begin{abstract}
Background: Roadmap 1.0 is a mobile health app that was previously developed for caregivers of patients who have undergone hematopoietic stem cell transplantation (HSCT). Formative research targeted toward its end users (caregivers) can help inform app design and development, allowing additional components to be incorporated into the app, which can then be tested in a future randomized controlled trial.
\end{abstract}

Objective: This study aimed to create a methodologically rigorous national survey that would help inform the development of Roadmap 2.0.

Methods: We conducted a prospective, qualitative research study that took place between November 18, 2018, and February 7, 2019, in a blood and marrow transplant unit within a large academic medical institution in the midwestern part of the United States. Cognitive interviews, including think-aloud and verbal probing techniques, were conducted in 10 adult caregivers $(\geq 18$ years) of patients who had undergone HSCT.

Results: Most participants were female $(9 / 10,90 \%)$, white $(9 / 10,90 \%)$, married $(9 / 10,90 \%)$, employed at least part time $(6 / 10$, $60 \%)$, caregivers of adult patients $(7 / 10,70 \%)$, and had some college education $(9 / 10,90 \%)$ and an annual household income of $\$ 60,000$ or higher $(6 / 10,60 \%)$. All but one interview was audio-recorded, with permission. Overall, participants were engaged in the cognitive interview process of the draft survey, which included 7 topics. The interviews highlighted areas wherein survey items could be further refined, such as offering more response choices (eg, "NA") or clarifying the type of transplant (eg, autologous or allogeneic) or context of transplant care (eg, pre-HSCT, during HSCT, post-HSCT, inpatient, and outpatient). Apart from these findings, the items in demographics, caregiving experiences, technology, positive activities, and mood were generally interpreted as intended. On the basis of the transcript data and field notes by the interviewer, items within self-efficacy (Caregiver Self-Efficacy Scale) and coping (Brief Coping Orientation to Problems Experienced inventory) questionnaires generated more confusion among interviewer and participants, reflecting difficulties in interpreting the meaning of some survey items.

Conclusions: This study incorporated the four cognitive aspects of survey methodology that describe the question-answering process-(1) comprehension, (2) information retrieval, (3) judgment and decision making, and (4) responding — by using the 
think-aloud and probing techniques in cognitive interviews. We conclude that this methodologically rigorous process informed revisions and improved our final questionnaire design.

International Registered Report Identifier (IRRID)： RR2-10.2196/resprot.49188

(JMIR Form Res 2020;4(1):e17077) doi: 10.2196/17077

\section{KEYWORDS}

hematopoietic stem cell transplantation; caregivers; mobile applications; qualitative research

\section{Introduction}

\section{Background}

Millions of individuals depend on family caregivers to manage their care [1]. Although family caregivers are a central part of health care [2], they often are invisible in our health care system, so much so that they are sometimes referred to as "hidden patients" [3]. The economic value of unpaid hours of care by family caregivers was estimated at US $\$ 470$ billion in 2013, and their contributions continue to intensify [4]. Indeed, with the aging population in the United States and the rising need for caregivers, efforts to foster caregiver health and well-being are essential for sustaining long-term care [5]. Caregivers assist patients with a wide range of activities, including managing complex medical tasks, organizing care plans, and advocating on their behalf [3]. These demands are of a time- and labor-intensive nature, and they place caregivers at high risk for injury and adverse events [3,6-8]. Addressing the needs of at-risk caregivers is an urgent public health priority [1].

Caregiver burden is defined as the "negative reaction to the impact of providing care on the caregiver's social, occupational, and personal roles" [9]. Much focus has been placed on the wide range of negative implications associated with caregiving [10] (eg, depression and anxiety) [11]. Despite this, most caregivers have recognized the benefits of caregiving [12,13]. The imbalance of focusing primarily on negative aspects may limit our ability to develop new assessment and intervention methods [14]. Thus, a "corrective focus" is needed in caregiving research to expand our knowledge on the positive aspects of caregiving $[15,16]$. Research on self-management suggests that self-efficacy, a positive aspect, can promote caregiver health, well-being, and positive health behaviors (ie, improved sleep and physical activity) [17,18].

The positive aspects of caregiving may explain how caregivers can positively engage patients in self-care activities [19]. Caregivers with better self-efficacy and well-being (ie, health-related quality of life) may positively affect patients' health outcomes [20-22]. Simple strategies aimed at enhancing positive thoughts, emotions, and behaviors have been shown to be effective and highly scalable [23-25]. Positive activity interventions, such as daily positive reflection, using gratitude journals, and conducting acts of kindness, have been used in the management of heart disease, cancer, diabetes, and chronic pain [26-29].

Blood and marrow transplant (BMT), commonly referred to as hematopoietic stem cell transplant (HSCT), is an intense but potentially curative therapy for a number of life-threatening blood diseases [30]. Given the high risk associated with BMT, a dedicated caregiver is necessary and expected for at least the first 100 days after the transplant [31]. However, HSCT caregivers are often unprepared for this role; it is not surprising that HSCT caregivers experience significant levels of anxiety and distress, especially during the peritransplant period [32,33]. Psychoeducational, skills training, and therapeutic counseling interventions have been shown to benefit caregiver health and well-being [34]. However, major barriers in translating successful interventions to clinical practice have included (1) limited understanding of the mechanism of action of an intervention and the (2) need for expert trainers, intensive training, and monitoring [3]. Interventions that are mechanism focused, low cost, and sustainable are needed [35].

We recently developed BMT Roadmap (Roadmap 1.0) as a mobile health (mHealth) app to provide patient-specific information, education, and skill-building exercises for caregivers to use during their inpatient stay. The modular components included patient-specific disease characteristics (eg, infectious disease markers, blood type, donor characteristics, and conditioning chemotherapy regimen), laboratory studies (ie, results shown in real time), medications (ie, lists of medications grouped according to indication, eg, antibiotic or antiemetic), clinical trials (ie, easy-to-read description of clinical trials and copies of informed consents), and a health care provider directory (ie, photographs of nurses, physicians, social workers, pharmacists, and nutritionists) in a yearbook style. To date, more than 100 HSCT caregivers have enrolled in institutional review board-approved studies to assess the feasibility of implementing Roadmap 1.0. Major themes that emerged from qualitative interviews conducted with users of Roadmap 1.0 included the following: (1) Roadmap 1.0's usefulness, ease of use, and likeability; (2) positive aspects of caregiving (ie, benefits of providing care); and (3) desire to expand Roadmap 1.0 to the outpatient setting, specifically targeting "caregiver-specific resources" and "positive activities" components [36-40].

\section{Objective}

Thus, in addition to the qualitative research findings from our single institution, we sought to develop a national caregiver health survey that could be broadly distributed to a diverse sample of HSCT caregivers. The goal of the survey was to examine design considerations for an outpatient version of Roadmap 1.0 (will be referred to as Roadmap 2.0 henceforth). Specifically, our intention was to develop a useful and understandable survey aimed at HSCT caregivers as the target audience. Thus, the aim of this study was to create a methodologically rigorous, broadly national survey that would help further inform the development of the app, in addition to contributing to substantive empirical research on caregivers of 
patients who have undergone HSCT. To do this, we conducted cognitive interviews to assess each survey item and adjusted, iterated, and rewrote the survey thereafter, which we report herein.

Figure 1. Study phases, methods, and references to published works. HCT: hematopoietic stem cell transplant.

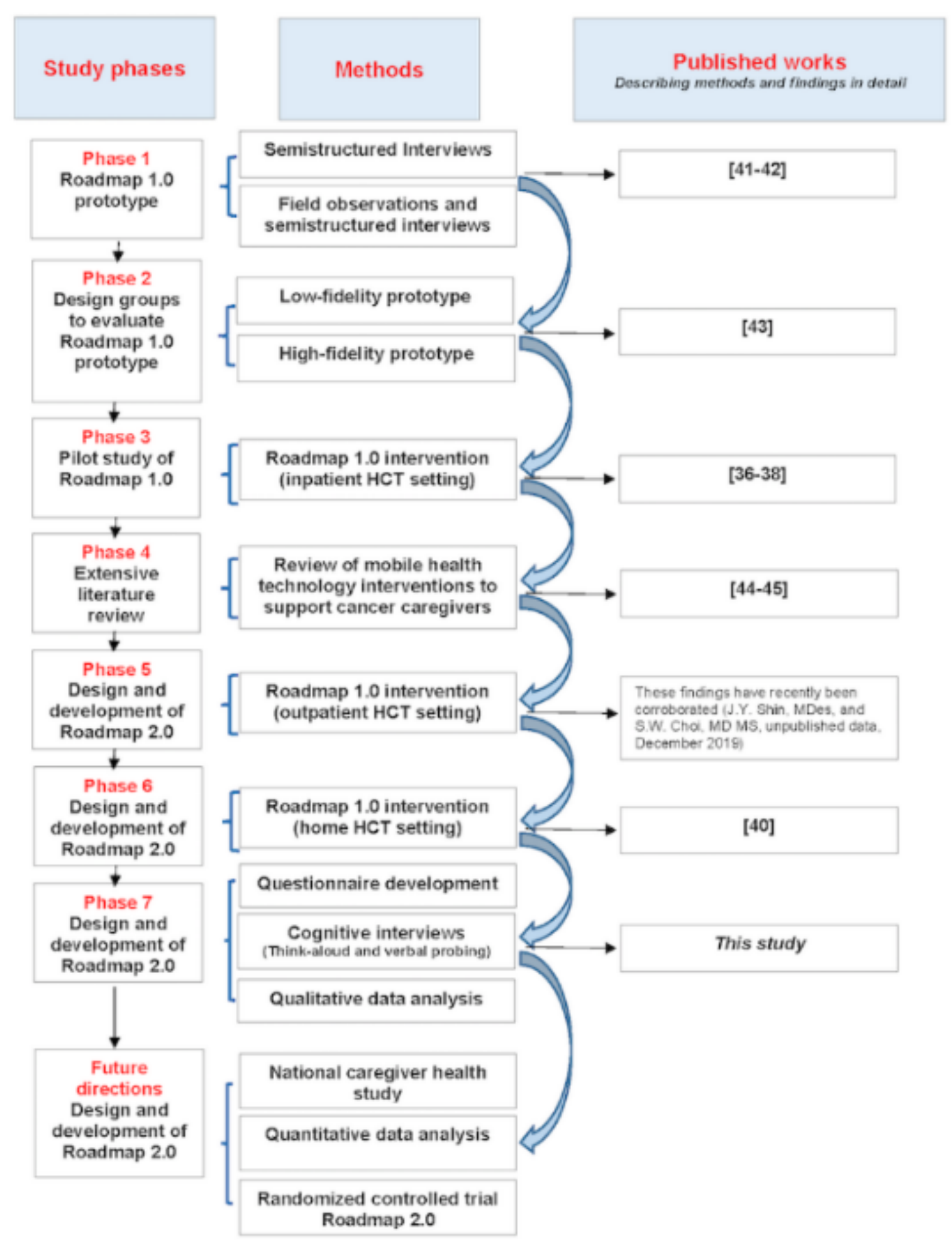

\section{Methods}

\section{Survey Development Process}

This work is part of a multiphase project (Figure 1) that will develop and test Roadmap 2.0 in a randomized controlled trial.
Development of the Caregiver Health Survey was based on included (1) demographics, (2) general caregiving duties and research derived from phases 1 to 6 [36-38,40-45]. The 6 sequential phases led to the development of a draft survey that 
enrichment through positive psychology-based activities, (5) mood, (6) confidence in providing care for a loved one (patient) and self-care (self-efficacy), and (7) ability to handle stress and use coping strategies. For items 5 to 7 , we incorporated the Patient Health Questionnaire [46], Caregiver Self-Efficacy Scale (CaSES) [47], and Brief Coping Orientation to Problems Experienced (COPE) inventory [48], with permission. The psychometric properties of these instruments are provided in Multimedia Appendix 1.

To ensure that survey items were clearly worded and provided contextualized understanding relevant to HSCT caregiving experiences, we conducted cognitive interviews. In short, the cognitive interview is based on the conceptual frameworks and methods in cognitive and social psychology [49]. As it is an important method used in survey development, particularly under the cognitive aspects of survey methodology (CASM), this approach was used in our survey design to ensure the quality and interpretability of question items [50]. We evaluated interviews using the 4 CASM steps that describe the question-answering process: (1) comprehension, (2) information retrieval, (3) judgment and decision making, and (4) responding [51].

During cognitive interviews, the interviewer read aloud each item and asked the participant to express any questions or concerns regarding the item. The interviewer used both think-aloud interview and verbal probing techniques. Think-aloud interviewing provided an opportunity for open-ended answers without interviewer direction. Verbal probing was used after the participant answered the think-aloud interview to provide further insight into the response [49-51]. In addition, the interviewer recorded field notes or observations from each interview session and also documented handwritten notes after reading each item out loud to the participant.

\section{Study Recruitment and Informed Consent}

The study was approved by the institutional review board (HUM00115569). Cognitive interviews were conducted with family caregivers of patients of the BMT unit of a large academic medical center in the midwestern part of the United States. Eligibility conditions for study participation were that the subject should be (1) the primary family caregiver who had already experienced the transplant procedure with their loved one (patient) and was in the posttransplant phase of care, (2) aged $\geq 18$ years, and (3) comfortable with reading and speaking English. Participants were recruited through referrals from the clinical team (eg, physician or advanced practitioner). The clinical team recruited caregivers who met eligibility criteria from the inpatient and outpatient settings. Only one caregiver declined participation; another caregiver signed the informed consent but was not available on the interview day. Thus, a total of 10 caregivers signed the informed consent and participated in the study.
The cognitive interviews took place between November 19, 2018, and February 7, 2019. Each interview session was approximately 30 to $50 \mathrm{mins}$ in length and was audio-recorded, with permission, and subsequently professionally transcribed (Babbletype LLC). One caregiver participant refused audio-recording. Participants were compensated with a $\$ 10$ gift card for their participation. A trained project manager with a background in survey methodology (Survey Research Operations, Survey Research Center, Institute of Social Research) moderated the cognitive interviews in a private hospital conference room. The interviewer was not affiliated with the BMT program. Recruitment ended once it was determined that no new data were being identified that informed the content of the survey items. Saturation was defined as a criterion for discontinuing data collection and/or analysis [52].

\section{Data Analysis}

The analysis approach included 3 steps. First, two experts in public health and survey methodology (Survey Research Operations, Survey Research Center, Institute of Social Research), neither affiliated with the BMT program, read the audio-recorded transcripts and the observation and summary notes of each survey item independently. They generated their own notes of each survey item, met together to compare notes, and provided suggested edits (ie, changes to survey items) to the research team. Second, the research team reviewed the results, validated the interpretations and conclusions in a peer-debriefing session, and developed a revised draft survey. Third, a survey methodologist at an external survey research organization (Center for Survey Research) reviewed all of the observation and summary notes and draft survey and provided additional edits of the draft survey. All changes to survey items that led to the final survey were made in collaboration with the lead study investigator.

\section{Results}

\section{Participant Demographics}

As shown in Table 1, the median age of the study participants was 57 years (range: 35-70 years). Most participants were recruited from the inpatient setting $(7 / 10,70 \%)$, female $(9 / 10$, $90 \%)$, white $(9 / 10,90 \%)$, married $(9 / 10,90 \%)$, caregivers of adult patients who had undergone HSCT $(7 / 10,70 \%)$, and employed at least part time $(6 / 10,60 \%)$ and had some college education $(9 / 10,90 \%)$ and an annual household income of $\$ 60,000$ or higher $(6 / 10,60 \%)$. Detailed demographics are provided in Multimedia Appendix 2. Overall, participants were engaged in the cognitive interview process. The findings are described below per survey topic. A list of questionnaire items from which the quotes were derived is provided in Multimedia Appendix 3. 
Table 1. Demographics of the study participants $(\mathrm{N}=10)$.

\begin{tabular}{|c|c|}
\hline Demographics & Values \\
\hline Age (years), median (SE); range & 52.4 (13.99); 35-70 \\
\hline \multicolumn{2}{|l|}{ Sex, n (\%) } \\
\hline Male & $2(20)$ \\
\hline Female & $8(80)$ \\
\hline \multicolumn{2}{|l|}{ Race and ethnicity, n (\%) } \\
\hline Non-Hispanic white & $9(90)$ \\
\hline Non-Hispanic black & $0(0)$ \\
\hline Hispanic & $1(10)$ \\
\hline Other or multiple & $0(0)$ \\
\hline \multicolumn{2}{|l|}{ Marital status, n (\%) } \\
\hline Married or in domestic partnership & $9(90)$ \\
\hline Divorced & $1(10)$ \\
\hline Single & $0(0)$ \\
\hline \multicolumn{2}{|l|}{ Highest level of schooling, n (\%) } \\
\hline High school graduate or general education diploma & $1(10)$ \\
\hline Some college or 2-year college degree & $3(30)$ \\
\hline 4-year college graduate & $1(10)$ \\
\hline More than 4-year college degree & $5(50)$ \\
\hline \multicolumn{2}{|l|}{ Current employment status, n (\%) } \\
\hline Employed part time (up to 39 hours/week) & $1(10)$ \\
\hline Employed full time (40 or more hours/week) & $4(40)$ \\
\hline Self-employed or unable to work & $1(10)$ \\
\hline Homemaker & $0(0)$ \\
\hline Unemployed and not currently looking for work & $0(0)$ \\
\hline Retired & $4(40)$ \\
\hline \multicolumn{2}{|l|}{ Annual household income, n (\%) } \\
\hline$\$ 0-30,001$ & $1(10)$ \\
\hline$\$ 30,001-60,000$ & $2(20)$ \\
\hline$\$ 60,001-100,000$ & $4(40)$ \\
\hline$\$ 100,001-200,000$ & $2(20)$ \\
\hline Greater than $\$ 200,000$ & $1(10)$ \\
\hline Prefer not to answer & $0(0)$ \\
\hline
\end{tabular}

\section{Survey Topic}

\section{Demographics}

Most caregiver participants were able to respond to demographic items in the survey with ease. A minor finding suggested to include additional response options:

Interviewer: Here's, "Other (please specify....)." I didn't see, but still, daughter, that seems like it should have an answer choice.

Participant: Probably pretty common. [Caregiver \#06]
A survey item asked, "How long ago did the patient receive an allogeneic transplant?" However, caregivers expressed that type of transplant could include autologous (eg, self) or allogeneic (eg, another related donor or another unrelated donor):

Interviewer: Who donated the stem cells for the patient's transplant? Was it a related donor? An unrelated donor? Or do you know?

Participant: The patient themselves (this refers to autologous transplant). [Caregiver \#07] 


\section{Caregiving Experiences}

In this section, caregivers expressed that some of the items were not applicable to their caregiving experiences as they were caring for their loved ones (care recipients or patients) at different stages of the transplant. For example, questions about hours spent caregiving did not make sense for a caregiver whose patient was currently hospitalized, undergoing the transplant procedure (ie, care mostly provided by a nurse):

Participant: How long have I been providing care?

Interviewer: $\mathrm{Mm}$-hmm (agreement).

Participant: Thirty-five years, but for this (transplant), a month. Almost, three weeks.

Interviewer: How many hours of caregiving have you provided per week for the patient?

Participant: I've probably been here (in the hospital) for 10 hours a day, so 70. [Caregiver \#08]

\section{Technology}

Items in this section were considered straightforward and easy to understand by participants. For example, most of the items were quantitative (ie, "How many apps do you use daily?"), and there were no major sources of confusion identified in this section. However, some of the items allowed for only a "Yes" or "No" response, but caregivers preferred a neutral response and suggested a "maybe," "not applicable (NA)," or "I am not sure" option:

Interviewer: That's okay, it's not an answer choice, but I can put that was your first response because that's not a choice. Which is closer, yes or no, to what you would do?

Participant: I would use it sometimes, so yes. [Caregiver \#03]

Interviewer: If a caregiver app existed, would you want the app to connect with other caregivers undergoing similar experiences in the transplant experience?

Participant: Sure...I wouldn't mind texting back and forth. The one-on-one face time I wouldn't necessarily want to do.

Interviewer: Do you feel like maybe you would need a different answer choice like yes, no, or maybe? Participant: Maybe. [Caregiver \#10]

\section{Personal Enrichment Through Positive Activity Exercises}

In this section, participants were asked to rate positive psychology activities based on their usefulness and how likely they were to participate in them. Participants were asked to provide a rating for each activity by indicating a response on a scale from 1 (extremely unlikely) to 5 (extremely likely). All of the participants were able to clearly articulate a score. This section was considered straightforward:

Interviewer: Exercise one. I'll just read through the exercise, and you can tell me on a scale of one to five, how willing you would be able to do the exercise. In exercise one, you would be asked to spend a few minutes each day savoring at least two everyday experiences such as morning coffee, the warmth of the sunshine, a call from a friend. You are to be mindful, very aware of the moment while savoring the experience and using all of your senses, sight, hearing, taste, and touch to solidify the memory. Please rate this activity on a scale of one to five, one, extremely unlikely, two, moderately unlikely, three, neither unlikely or likely, four, moderately likely, five, extremely likely.

Participant: Four.

Interviewer: Four?

Participant: Yes. [Caregiver \#03]

Interviewer: Exercise two. In this activity, every evening you would think about the things that made you happy that day. You would write down one of these moments on a piece of paper, fold up this piece of paper and drop it into a piggy bank. We would provide the piggy bank. At the end of 30 days, you would close your account, which means you would open the piggy bank and read and savor all of the deposited happy memories. On a scale of one to five, extremely unlikely, moderately unlikely?

Participant: Probably one.

Interviewer: Extremely unlikely. [Caregiver \#04]

\section{Mood}

This section included 4 items, which were previously developed in a US sample of 2149 patients from 15 primary care sites [46]. Overall, the items were considered straightforward and easy to follow. Participants seemed to have little to no difficulty following this section's directions, and they did not express significant concerns about the intent of the items. However, several participants commented that the 4 response options (eg, "not at all," "several days," "more than half the days," and "nearly every day") were not adequate (ie, a fifth option, such as "every day," should be included). A participant declined to provide a response because she did not feel comfortable answering some of the items in this section to the interviewer:

Participant: I'm pretty private. I know that seems weird because I'm doing this study.

Interviewer: This is private. [Caregiver \#01]

\section{Confidence in Providing Care to a Loved One (Patient) and Self-Care}

The CaSES questionnaire has been previously studied in caregivers of patients with advanced cancer [47]. Participants commented that some of the items in this section were framed with assumptions about the caregivers' experiences (ie, caregiver of adult vs pediatric patient). Some of the experiences did not apply to all of the participants, depending on the transplant phase (eg, pre-HSCT, during HSCT, or post-HSCT). Most of the caregivers needed clarification on the response options and alluded to needing an "NA" response option: 
Interviewer: That's helpful. Continue to provide care when you feel scared?

Participant: Yes, I can. It's more about willing and able and definitely will do it, but we haven't been. Interviewer: You haven't been scared yet?

Participant: Not yet. [Caregiver 06]

Interviewer: How about angry? Continue to provide care when you feel angry?

Participant: That hasn't happened. [Caregiver \#06]

\section{Ability to Handle Stress and Use Coping Strategies}

Participants encountered the most difficulty in interpreting items in this section related to the Brief COPE questionnaire, which has been previously studied in family caregivers of women with advanced breast cancer [48]. Participants reported frustration in responding to questions, such as "I've been looking for something good in what is happening" or "I've been making fun of the situation," as they appeared to be insensitive to their journey.

Again, similar to the self-efficacy items, when responding to the coping-related items, acknowledging the caregivers' frame of reference was important (ie, defining whether the items refer to the pre-HSCT, during HSCT, or post-HSCT setting, or more generally, in the midst of a stressful event). Medical, personal (patient), and family goals also influenced how participants responded to certain items. For example, for some patients, the goal was to work toward more independence. For others, caregivers were instructed to provide as much help as possible to reduce patient suffering:

\section{Interviewer: I've been taking action to try and make the situation better.}

Participant: That's the same thing. To me, that question implies a parent could have done something to make it better. It feels like a crappy question. It makes me feel bad like I should have done something differently or I should have taken action to make this better. In reality, parents don't have control over this. [Caregiver \#02]

\section{Discussion}

\section{Principal Findings}

In this study, we report the findings of cognitive interviews conducted in caregivers of patients who had undergone HSCT that assessed each survey item. Following the 4 CASM steps that describe the question-answering process-(1) comprehension, (2) information retrieval, (3) judgment and decision making, and (4) responding and using the think-aloud and probing techniques — we found that this methodologically rigorous process informed revisions and improved our final questionnaire design. Indeed, evidence-based data have shown that pilot testing a survey is typically insufficient to ensure the quality and accuracy of the questionnaire [49].

Some of the participants identified confusion within certain sections of the survey that may have been missed with pilot testing alone. Interestingly, the sections that prompted the most concerns were the CaSES and Brief COPE items. For example, the wording of some of items created confusion for our participants, which may have been because of the context of care that is unique to HSCT (eg, pre-HSCT, during HSCT, post-HSCT, inpatient, outpatient, caregiver of an adult patient, or caregiver of a pediatric patient). Thus, this led to the following changes: (1) inclusion of more succinct and clear instructions in the introduction or preamble to each section; (2) incorporation of anchoring terms, such as "at the time of transplant"; and (3) inclusion of questionnaire items tailored to the HSCT population (ie, to better align the items to HSCT, we deleted some items that repeatedly raised concerns in the participants).

Importantly, the interviews revealed that the original set of items was not exhausted and highlighted areas wherein survey items could be further refined by (1) offering more response choices (eg, "NA"), (2) removing some negatively worded items, (3) including more items to make our points clear, (4) moving the order of some items so that it flowed more clearly within each topic, and (5) collapsing redundant items (eg, collapsing income brackets/categories). Thus, we found that during the course of this study, we were able to examine item interpretation and readability and adjust, refine, and rewrite items that would be understood correctly by future survey respondents. We also redesigned the formatting of certain sections by (1) creating a grid or matrix question format with $\mathrm{x}$-axis that listed the item and $y$-axis that listed the response options, (2) developing a single-response or "radio-question" format, and (3) auto-populating or piping in the patient's name from a previous response to further reduce the readability burden. Personal enrichment through positive activity exercises did not identify any potential problems that might lead to survey response error, and thus, no further changes were made to any of its items.

\section{Comparison With Prior Work}

Overall, we found that participants were willing to contribute to this type of project, specifically to help future caregivers who would undergo this process, which was consistent with our prior research [53]. Participants of this study were caregivers of both adult and pediatric patients who had undergone BMT. The cognitive interviews identified areas that helped us refine language to allow for interpretability regardless of caregiver type (eg, adult or pediatric). Prior HSCT survey reports have examined either adult or pediatric HSCT [54,55]. Thus, our findings offer a unique contribution to the literature.

Conducting cognitive interviews and using techniques such as think-aloud can help us to learn how participants interpret questionnaire items in their own words, thereby facilitating the development of an instrument that is discriminating, reliable, and valid. de Leeuw et al conducted 2 recent studies [56,57] using a rigorous methodological process that included cognitive interviews in the development of an instructional design evaluation survey. Our findings herein support the use of such rigorous processes in developing surveys that verify how participants are interpreting survey items and whether the survey format and response sets are understandable. 


\section{Strengths and Limitations}

Major strengths of the study include the development of a refined survey through rigorous methodology that involved a trained interviewer, experts in qualitative data analysis through the lens of survey methodology (and not affiliated with the BMT study population), a research team with extensive knowledge in the BMT study population, and an external survey methodology research investigator (not affiliated with our institution). Not involving survey methodology experts in our study population helped remove biases in the interpretation of our findings.

On the basis of the review of the transcript data and field notes captured by the moderator, we found that the think-aloud technique was successful in capturing constructive feedback, particularly related to the self-efficacy and coping-related items. Participants freely shared that some items were not pertinent to them, insensitively phrased, or required more response options. Verbal probing revealed items that caused confusion (ie, the participant was stuck or paused for a long time, and the interviewer posed a clarifying question or comment to identify the confusion). Overall, the probes were not directive, and participants were able to verbalize their thoughts freely and openly. In the instances that participants refused to answer an item (ie, because of the insensitive nature of the survey item or privacy concerns), the moderator did not probe further. For example, a caregiver declined to answer the 4 psychological distress items because of privacy concerns. It is possible that survey quality will improve in the future with an anonymous, self-administered survey (ie, removing the interviewer).

Despite our extensive work to develop a survey that would be reliable and interpretable, we recognize the limitations of our work. First, participants who were engaged in this research participated in our research. All but one caregiver agreed to participate when approached by the clinical care team, which may reflect social desirability to please the health care providers. In addition, this could mean that our data were skewed by selective input of those engaged in research. Most participants were white, female, married, and highly educated. We recognize that caregiving experiences could be different based on race, gender, and other identities. Our study was also conducted in a single institution in a midwestern location in the United States. The location could change the needs of a community, and a single-institution study could have reflected the interpretation of individuals attending our center. Although cognitive interviews were conducted to improve questionnaire design and to inform revisions, it is likely that some individuals may still have difficulty interpreting some items as intended, which could lead to inaccurate responses or missing data, if left unanswered.

Nonetheless, findings from our cognitive interviews were invaluable in the refinement of our final Caregiver Health Survey. In general, interventions to support caregivers longitudinally across the trajectory of care are limited. Our larger research agenda aims to contribute to the intervention literature. We hope that the findings from our study, which highlight the importance of cognitive interviews, will be useful for research investigators designing surveys with caregivers in mind, especially surveys in support of developing health interventions. Furthermore, in-depth explorations of survey items by asking caregivers about their perceptions provided them with an important opportunity to include them as active partners in the care of their loved ones (patients). Sharing these data about caregivers' views of survey items and what their thought processes are when responding to items may also facilitate future caregiving work.

\section{Future Research}

The main goal of this study was to create a survey that will inform the development of our future Roadmap 2.0 app and continue research on mHealth interventions. Data collected herein informed our national caregiver health survey, which was deployed nationally from May to June 2019 (data analyses are forthcoming). Although this investigator-initiated survey queried respondents on health behavior and use of mHealth apps generally to inform our Roadmap 2.0 app, once developed and tested, we anticipate using one of the many recent well-developed and well-validated surveys, such as the Health Information Technology Usability Evaluation Scale [58], mHealth App Usability Questionnaire [59], and/or the Mobile App Rating Scale [60], to assess the app's usability.

\section{Acknowledgments}

This work was supported by an American Society of Hematology Bridge Grant and National Institutes of Health/National Heart, Lung, and Blood Institute grant (1R01HL146354) and the Edith S Briskin and Shirley K Schlafer Foundation (Sung Won Choi). The authors wish to thank caregivers who participated in this study.

\section{Authors' Contributions}

JK, SK, DC, RV, GC, JS, and DH contributed to data curation, data analysis, and reviewing and editing of manuscript drafts. AM contributed to patient recruitment, data curation, and reviewing and editing of manuscript drafts. MO contributed to data collection, data curation, data analysis, data interpretation, visualization, and reviewing and editing of manuscript drafts. LY contributed to data analysis, data interpretation, visualization, and reviewing and editing of manuscript drafts. SC contributed to data curation, investigation, methodology, data analysis, resources, supervision, visualization, writing original draft, and reviewing and editing of manuscript drafts.

\section{Conflicts of Interest}

None declared. 


\section{Multimedia Appendix 1}

Psychometric properties of the Patient Health Questionnaire-4, Caregiver Self-Efficacy Scale, and Brief Coping Orientation to Problems Experienced inventory.

[DOCX File, 23 KB-Multimedia Appendix 1]

\section{Multimedia Appendix 2}

Detailed demographics of study participants.

[DOCX File, 14 KB-Multimedia Appendix 2]

\section{Multimedia Appendix 3}

List of questionnaire items from which the quotes were derived.

[DOCX File, 16 KB-Multimedia Appendix 3]

\section{References}

1. National Alliance for Caregiving in Collaboration with AARP Public Policy Institute. 2015. Executive Summary of Caregiving in the US 2015 URL: http://www.caregiving.org/wp-content/uploads/2015/05/

2015 CaregivingintheUS Final-Report-June-4 WEB.pdf [accessed 2019-12-24]

2. Family Caregiver Alliance, National Center on Caregiving. 2019. Caregiver Statistics: Demographics URL: https://www. caregiver.org/caregiver-statistics-demographics [accessed 2019-12-24]

3. Reinhard SC, Given B, Petlock NH, Bemis A. Supporting family caregivers in providing care. In: Hughes RG, editor. Patient Safety and Quality: An Evidence-Based Handbook for Nurses. Rockville, MD: Agency for Healthcare Research and Quality; Apr 2008:I-341-I-404.

4. Reinhard SC, Feinberg LF, Choula R, Houser A. AARP Public Policy Institute. 2015 Jul. Valuing the invaluable: 2015 update URL: https://www.aarp.org/content/dam/aarp/ppi/2015/valuing-the-invaluable-2015-update-new.pdf [accessed 2019-12-24]

5. Talley RC, Crews JE. Framing the public health of caregiving. Am J Public Health 2007 Feb;97(2):224-228. [doi: 10.2105/AJPH.2004.059337] [Medline: 17194871]

6. Vitaliano PP, Zhang J, Scanlan JM. Is caregiving hazardous to one's physical health? A meta-analysis. Psychol Bull 2003 Nov;129(6):946-972. [doi: 10.1037/0033-2909.129.6.946] [Medline: 14599289]

7. Lee S, Colditz GA, Berkman LF, Kawachi I. Caregiving and risk of coronary heart disease in US women: a prospective study. Am J Prev Med 2003 Feb;24(2):113-119. [doi: 10.1016/s0749-3797(02)00582-2] [Medline: 12568816]

8. Schulz R, Newsom J, Mittelmark M, Burton L, Hirsch C, Jackson S. Health effects of caregiving: the caregiver health effects study: an ancillary study of the Cardiovascular Health Study. Ann Behav Med 1997;19(2):110-116. [doi: 10.1007/BF02883327] [Medline: 9603685]

9. Given BA, Given CW, Kozachik S. Family support in advanced cancer. CA Cancer J Clin 2001;51(4):213-231 [FREE Full text] [doi: 10.3322/canjclin.51.4.213] [Medline: 11577488]

10. Pinquart M, Sörensen S. Differences between caregivers and noncaregivers in psychological health and physical health: a meta-analysis. Psychol Aging 2003 Jun;18(2):250-267. [doi: 10.1037/0882-7974.18.2.250] [Medline: 12825775]

11. Barata A, Wood WA, Choi SW, Jim HS. Unmet needs for psychosocial care in hematologic malignancies and hematopoietic cell transplant. Curr Hematol Malig Rep 2016 Aug;11(4):280-287. [doi: 10.1007/s11899-016-0328-z] [Medline: 27113094]

12. Farran CJ, Keane-Hagerty E, Salloway S, Kupferer S, Wilken CS. Finding meaning: an alternative paradigm for Alzheimer's disease family caregivers. Gerontologist 1991 Aug;31(4):483-489. [doi: 10.1093/geront/31.4.483] [Medline: 1894152]

13. Sanders $\mathrm{S}$. Is the glass half empty or full? Reflections on strain and gain in cargivers of individuals with Alzheimer's disease. Soc Work Health Care 2005;40(3):57-73. [doi: 10.1300/J010v40n03 04] [Medline: 15837668]

14. Northouse LL. The impact of cancer on the family: an overview. Int J Psychiatry Med 1995 Jan;14(3):215-242. [doi: 10.2190/c8y5-4y2w-wv93-qdat]

15. Miller B, Lawton MP. Finding balance in caregiver research - Introduction. Gerontologist 1997 Apr;37(2):216-217 [FREE Full text]

16. Mosher CE, Adams RN, Helft PR, O'Neil BH, Shahda S, Rattray NA, et al. Positive changes among patients with advanced colorectal cancer and their family caregivers: a qualitative analysis. Psychol Health 2017 Jan;32(1):94-109 [FREE Full text] [doi: 10.1080/08870446.2016.1247839] [Medline: 27775432]

17. Au A, Lau K, Sit E, Cheung G, Lai M, Wong SK, et al. The role of self-efficacy in the Alzheimer's family caregiver stress process: a partial mediator between physical health and depressive symptoms. Clin Gerontol 2010 Aug 31;33(4):298-315. [doi: $10.1080 / 07317115.2010 .502817]$

18. Northouse L, Williams A, Given B, McCorkle R. Psychosocial care for family caregivers of patients with cancer. J Clin Oncol 2012 Apr 10;30(11):1227-1234. [doi: 10.1200/JCO.2011.39.5798] [Medline: 22412124] 
19. Badr H, Yeung C, Lewis MA, Milbury K, Redd WH. An observational study of social control, mood, and self-efficacy in couples during treatment for head and neck cancer. Psychol Health 2015;30(7):783-802 [FREE Full text] [doi: 10.1080/08870446.2014.994633] [Medline: 25471820]

20. Northouse LL, Katapodi MC, Schafenacker AM, Weiss D. The impact of caregiving on the psychological well-being of family caregivers and cancer patients. Semin Oncol Nurs 2012 Nov;28(4):236-245 [FREE Full text] [doi: 10.1016/j.soncn.2012.09.006] [Medline: 23107181]

21. Keefe FJ, Ahles TA, Porter LS, Sutton LM, McBride CM, Pope MS, et al. The self-efficacy of family caregivers for helping cancer patients manage pain at end-of-life. Pain 2003 May;103(1-2):157-162. [doi: 10.1016/s0304-3959(02)00448-7] [Medline: 12749970]

22. Porter LS, Keefe FJ, Garst J, McBride CM, Baucom D. Self-efficacy for managing pain, symptoms, and function in patients with lung cancer and their informal caregivers: associations with symptoms and distress. Pain 2008 Jul 15;137(2):306-315 [FREE Full text] [doi: 10.1016/j.pain.2007.09.010] [Medline: 17942229]

23. Sin NL, Lyubomirsky S. Enhancing well-being and alleviating depressive symptoms with positive psychology interventions: a practice-friendly meta-analysis. J Clin Psychol 2009 May;65(5):467-487. [doi: 10.1002/jclp.20593] [Medline: 19301241]

24. Bolier L, Haverman M, Westerhof GJ, Riper H, Smit F, Bohlmeijer E. Positive psychology interventions: a meta-analysis of randomized controlled studies. BMC Public Health 2013;13:119 [FREE Full text] [doi: 10.1186/1471-2458-13-119] [Medline: 23390882]

25. Hassett AL, Finan PH. The role of resilience in the clinical management of chronic pain. Curr Pain Headache Rep 2016 Jun;20(6):39. [doi: 10.1007/s11916-016-0567-7] [Medline: 27115770]

26. Huffman JC, Mastromauro CA, Boehm JK, Seabrook R, Fricchione GL, Denninger JW, et al. Development of a positive psychology intervention for patients with acute cardiovascular disease. Heart Int 2011 Sep 29;6(2):e14 [FREE Full text] [doi: 10.4081/hi.2011.e14] [Medline: 23825741]

27. Moskowitz JT, Hult JR, Duncan LG, Cohn MA, Maurer S, Bussolari C, et al. A positive affect intervention for people experiencing health-related stress: development and non-randomized pilot test. J Health Psychol 2012 Jul;17(5):676-692 [FREE Full text] [doi: 10.1177/1359105311425275] [Medline: 22021272]

28. Cohn MA, Pietrucha ME, Saslow LR, Hult JR, Moskowitz JT. An online positive affect skills intervention reduces depression in adults with type 2 diabetes. J Posit Psychol 2014 Jan 01;9(6):523-534 [FREE Full text] [doi: 10.1080/17439760.2014.920410] [Medline: 25214877]

29. Hausmann LR, Parks A, Youk AO, Kwoh CK. Reduction of bodily pain in response to an online positive activities intervention. J Pain 2014 May;15(5):560-567. [doi: 10.1016/j.jpain.2014.02.004] [Medline: 24568751]

30. Copelan EA. Hematopoietic stem-cell transplantation. N Engl J Med 2006 Apr 27;354(17):1813-1826. [doi: 10.1056/NEJMra052638] [Medline: 16641398]

31. Laudenslager ML, Simoneau TL, Kilbourn K, Natvig C, Philips S, Spradley J, et al. A randomized control trial of a psychosocial intervention for caregivers of allogeneic hematopoietic stem cell transplant patients: effects on distress. Bone Marrow Transplant 2015 Aug;50(8):1110-1118 [FREE Full text] [doi: 10.1038/bmt.2015.104] [Medline: 25961767]

32. Bevans MF, Mitchell SA, Marden S. The symptom experience in the first 100 days following allogeneic hematopoietic stem cell transplantation (HSCT). Support Care Cancer 2008 Nov;16(11):1243-1254 [FREE Full text] [doi: 10.1007/s00520-008-0420-6] [Medline: 18322708 ]

33. Simoneau TL, Mikulich-Gilbertson SK, Natvig C, Kilbourn K, Spradley J, Grzywa-Cobb R, et al. Elevated peri-transplant distress in caregivers of allogeneic blood or marrow transplant patients. Psychooncology 2013 Sep;22(9):2064-2070 [FREE Full text] [doi: 10.1002/pon.3259] [Medline: 23440998]

34. Gemmill R, Cooke L, Williams AC, Grant M. Informal caregivers of hematopoietic cell transplant patients: a review and recommendations for interventions and research. Cancer Nurs 2011;34(6):E13-E21 [FREE Full text] [doi: 10.1097/NCC.0b013e31820a592d] [Medline: 21242762]

35. Committee on Family Caregiving for Older Adults. The National Academies of Sciences, Engineering, Medicine. 2016 Sep 13. Families Caring for an Aging America URL: http://www.nationalacademies.org/hmd/ /media/Files/Report\%20Files/ 2016/Caregiving-RiB.pdf [accessed 2019-12-24]

36. Runaas L, Hanauer D, Maher M, Bischoff E, Fauer A, Hoang T, et al. BMT roadmap: a user-centered design health information technology tool to promote patient-centered care in pediatric hematopoietic cell transplantation. Biol Blood Marrow Transplant 2017 May;23(5):813-819 [FREE Full text] [doi: 10.1016/j.bbmt.2017.01.080] [Medline: 28132870]

37. Runaas L, Hoodin F, Munaco A, Fauer A, Sankaran R, Churay T, et al. Novel health information technology tool use by adult patients undergoing allogeneic hematopoietic cell transplantation: longitudinal quantitative and qualitative patient-reported outcomes. JCO Clin Cancer Inform 2018 Dec;2:1-12 [FREE Full text] [doi: 10.1200/CCI.17.00110] [Medline: $\underline{30652535]}$

38. Fauer AJ, Hoodin F, Lalonde L, Errickson J, Runaas L, Churay T, et al. Impact of a health information technology tool addressing information needs of caregivers of adult and pediatric hematopoietic stem cell transplantation patients. Support Care Cancer 2019 Jun;27(6):2103-2112. [doi: 10.1007/s00520-018-4450-4] [Medline: 30232587]

39. Shin J, Kedroske J, Vue R, Sankaran R, Chaar D, Churay T, et al. Design considerations for family centered health management: preliminary findings with pediatric BMT patients. In: ACM Conference on Interaction Design and Children. 
2018 Presented at: Proceedings of the ACM Conference on Interaction Design in Children (IDC' 18). Trondheim, Norway; June 19-22, 2018; Trondheim, Norway. [doi: 10.1145/3202185.3210781]

40. Chaar D, Shin JY, Mazzoli A, Vue R, Kedroske J, Chappell G, et al. A mobile health app (Roadmap 2.0) for patients undergoing hematopoietic stem cell transplant: qualitative study on family caregivers' perspectives and design considerations. JMIR Mhealth Uhealth 2019 Oct 24;7(10):e15775 [FREE Full text] [doi: 10.2196/15775] [Medline: $\underline{31651402}$ ]

41. Kaziunas E, Buyuktur A, Jones J, Choi S, Hanauer D, Ackerman M. Transition and Reflection in the Use of Health Information: The Case of Pediatric Bone Marrow Transplant Caregivers. In: Conference on Computer Supported Cooperative Work \& Social Computing. 2015 Presented at: Proceedings of the ACM Conference on Computer Supported Cooperative Work (CSCW '15). Vancouver, British Columbia, Canada; March 14-18, 2015; Vancouver, BC, Canada. [doi: 10.1145/2675133.2675276]

42. Kaziunas E, Hanauer DA, Ackerman MS, Choi SW. Identifying unmet informational needs in the inpatient setting to increase patient and caregiver engagement in the context of pediatric hematopoietic stem cell transplantation. J Am Med Inform Assoc 2016 Jan;23(1):94-104 [FREE Full text] [doi: 10.1093/jamia/ocv116] [Medline: 26510878]

43. Maher M, Kaziunas E, Ackerman M, Derry H, Forringer R, Miller K, et al. User-centered design groups to engage patients and caregivers with a personalized health information technology tool. Biol Blood Marrow Transplant 2016 Feb;22(2):349-358 [FREE Full text] [doi: 10.1016/j.bbmt.2015.08.032] [Medline: 26343948]

44. Shin JY, Kang TI, Noll RB, Choi SW. Supporting caregivers of patients with cancer: a summary of technology-mediated interventions and future directions. Am Soc Clin Oncol Educ Book 2018 May 23;38:838-849 [FREE Full text] [doi: 10.1200/EDBK 201397] [Medline: 30231412]

45. Shin JY, Choi SW. Online interventions geared toward increasing resilience and reducing distress in caregivers and families. Curr Opin Support Palliat Care. Accepted, In Press; December 2019 (forthcoming)(forthcoming).

46. Kroenke K, Spitzer RL, Williams JB, Löwe B. An ultra-brief screening scale for anxiety and depression: the PHQ-4. Psychosomatics 2009;50(6):613-621. [doi: 10.1176/appi.psy.50.6.613] [Medline: 19996233]

47. Ugalde A, Krishnasamy M, Schofield P. Development of an instrument to measure self-efficacy in caregivers of people with advanced cancer. Psychooncology 2013 Jun;22(6):1428-1434. [doi: 10.1002/pon.3160] [Medline: 22941754]

48. Kershaw T, Northouse L, Kritpracha C, Schafenacker A, Mood D. Coping strategies and quality of life in women with advanced breast cancer and their family caregivers. Psychol Health 2007;19(2):139-155. [doi: $10.1080 / 08870440310001652687]$

49. Collins D. Pretesting survey instruments: an overview of cognitive methods. Qual Life Res 2003 May;12(3):229-238. [doi: 10.1023/a:1023254226592] [Medline: 12769135]

50. Presser S, Couper MP, Lessler JT, Martin E, Martin J, Rothgeb JM, et al. Methods for testing and evaluating survey questions. Public Opin Q 2004 Apr 22;68(1):109-130. [doi: 10.1093/poq/nfh008]

51. Willis G. Cognitive Interviewing: A Tool for Improving Questionnaire Design. Thousand Oaks, CA: Sage Publications; 2005.

52. Saunders B, Sim J, Kingstone T, Baker S, Waterfield J, Bartlam B, et al. Saturation in qualitative research: exploring its conceptualization and operationalization. Qual Quant 2018;52(4):1893-1907 [FREE Full text] [doi: 10.1007/s11135-017-0574-8] [Medline: 29937585]

53. Keusch F, Rao R, Chang L, Lepkowski J, Reddy P, Choi SW. Participation in clinical research: perspectives of adult patients and parents of pediatric patients undergoing hematopoietic stem cell transplantation. Biol Blood Marrow Transplant 2014 Oct;20(10):1604-1611 [FREE Full text] [doi: 10.1016/j.bbmt.2014.06.020] [Medline: 24972252]

54. Mayer DK, Tighiouart H, Terrin N, Stewart S, Peterson E, Jeruss S, et al. A brief report of caregiver needs and resource utilization during pediatric hematopoietic stem cell transplantation. J Pediatr Oncol Nurs 2009;26(4):223-229 [FREE Full text] [doi: 10.1177/1043454209340409] [Medline: 19726794]

55. Jamani K, Onstad LE, Bar M, Carpenter PA, Krakow EF, Salit RB, et al. Quality of life of caregivers of hematopoietic cell transplant recipients. Biol Blood Marrow Transplant 2018 Nov;24(11):2271-2276 [FREE Full text] [doi:

10.1016/j.bbmt.2018.06.015] [Medline: 29935213]

56. de Leeuw R, Scheele F, Walsh K, Westerman M. A 9-step theory- and evidence-based postgraduate medical digital education development model: empirical development and validation. JMIR Med Educ 2019 Jul 22;5(2):e13004 [FREE Full text] [doi: 10.2196/13004] [Medline: 31333194]

57. de Leeuw RA, Westerman M, Walsh K, Scheele F. Development of an instructional design evaluation survey for postgraduate medical e-learning: content validation study. J Med Internet Res 2019 Aug 09;21(8):e13921 [FREE Full text] [doi: 10.2196/13921] [Medline: 31400102]

58. Schnall R, Cho H, Liu J. Health Information Technology Usability Evaluation Scale (Health-ITUES) for usability assessment of mobile health technology: validation study. JMIR Mhealth Uhealth 2018 Jan 05;6(1):e4 [FREE Full text] [doi: 10.2196/mhealth.8851] [Medline: 29305343]

59. Zhou L, Bao J, Setiawan IM, Saptono A, Parmanto B. The mHealth App Usability Questionnaire (MAUQ): development and validation study. JMIR Mhealth Uhealth 2019 Apr 11;7(4):e11500 [FREE Full text] [doi: 10.2196/11500] [Medline: 30973342] 
60. Stoyanov SR, Hides L, Kavanagh DJ, Zelenko O, Tjondronegoro D, Mani M. Mobile app rating scale: a new tool for assessing the quality of health mobile apps. JMIR Mhealth Uhealth 2015 Mar 11;3(1):e27 [FREE Full text] [doi: 10.2196/mhealth.3422] [Medline: 25760773]
Abbreviations
BMT: blood and marrow transplant
CaSES: Caregiver Self-Efficacy Scale
COPE: Coping Orientation to Problems Experienced
HSCT: hematopoietic stem cell transplant
mHealth: mobile health

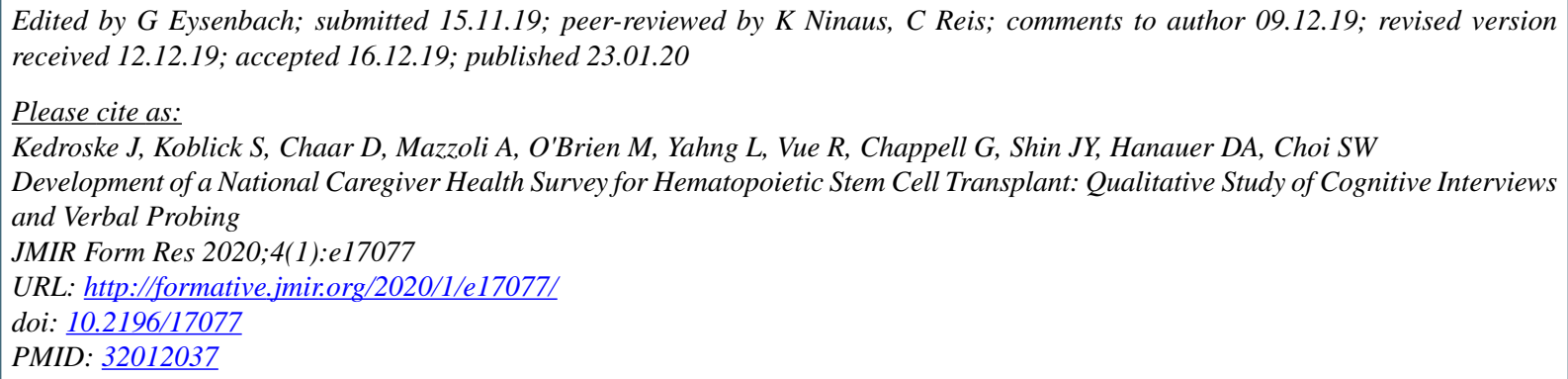

(CJacob Kedroske, Sarah Koblick, Dima Chaar, Amanda Mazzoli, Maureen O'Brien, Lilian Yahng, Rebecca Vue, Grant Chappell, Ji Youn Shin, David A Hanauer, Sung Won Choi. Originally published in JMIR Formative Research (http://formative.jmir.org), 23.01.2020. This is an open-access article distributed under the terms of the Creative Commons Attribution License (https://creativecommons.org/licenses/by/4.0/), which permits unrestricted use, distribution, and reproduction in any medium, provided the original work, first published in JMIR Formative Research, is properly cited. The complete bibliographic information, a link to the original publication on http://formative.jmir.org, as well as this copyright and license information must be included. 